\title{
Predictors of intentions to conserve bats among New York property owners
}

\author{
William F. Siemer ${ }^{a *}$, T. Bruce Lauber ${ }^{a}$, Heidi E. Kretser ${ }^{a}$, Krysten L. Schuler ${ }^{c}$, \\ Michelle Verant ${ }^{\mathrm{d}}$, Carl J. Herzog ${ }^{\mathrm{e}}$, and Katherine A. McComas ${ }^{\mathrm{f}}$
}

${ }^{a}$ Department of Natural Resources, Cornell University, Ithaca, USA; ${ }^{b}$ Wildlife Conservation Society, Bronx, USA; 'College of Veterinary Medicine, Cornell University, Ithaca, USA;

${ }^{d}$ Biological Resources Division, National Park Service, Fort Collins, USA; ${ }^{e}$ New York State Department of Environmental Conservation, Albany, USA; fCommunication Department, Cornell University, Ithaca, USA

*William F. Siemer, email: wfs1@,cornell.edu, G18 Fernow Hall, Department of Natural Resources, 226 Mann Drive, Cornell University, Ithaca, New York 14853

This work was supported by the Cornell Agricultural Experiment Station (Project No. NYC1477300) National Institute of Food and Agriculture [NIFA]), and by the Wildlife Management Institute (WMI) White-Nose Syndrome Small Grants Initiative (administered on $\mathrm{n}$ behalf of the US Fish and Wildlife Service [USFWS]). 


\section{Predictors of intentions to conserve bats among New York property owners}

Understanding why private property owners take actions to conserve bats has become increasingly important in U.S. states where the fungus causing white-nose syndrome (Pseudogymnoascus destructans) has decimated bat populations. We surveyed property owners in three New York State counties $(n=2,500)$ and used multiple linear regression analyses to test predictors of intentions to conserve bats. Intentions to take actions that contribute to bat conservation directly were predicted by severity of rabies consequences, sense of bat conservation self efficacy, beliefs about responsibility for bat conservation, and attitudes toward bats $\left(\mathrm{R}^{2}=.39\right)$. Intentions to take actions that conserve bats indirectly were predicted by biospheric value orientations, beliefs about responsibility for bat conservation, and attitudes toward bats $\left(\mathrm{R}^{2}=.27\right)$. The relationship between beliefs about rabies and intentions to take actions that contribute to bat conservation highlight the need for coordinated risk communication between public health and wildlife conservation organizations.

Keywords: bats; behavioral intention; protection motivation theory; rabies; white-nose syndrome 


\section{Introduction}

White-nose syndrome (WNS) is a highly contagious disease among bats caused by the fungus Pseudogymnoascus destructans (Blehert et al., 2009). Since it was first detected in upstate New York in 2006, WNS has caused the largest die-off of bats in North American history; more than 6 million bats have died due to the disease, which has mortality rates higher than $90 \%$ for some species (Froschauer \& Coleman, 2012). Scientists have documented the rapid and continuing spread of WNS across the U.S. (https://www.whitenosesyndrome.org/spreadmap).

This threat to bats affects people because bats provide economic and ecosystem services (Ghanem \& Voight, 2012; Kasso \& Balakrishnan, 2013, Kunz et al., 2011; Maine \& Boyles, 2015), including suppression of insect populations. Bats are prodigious consumers of insects that cause crop damage or serve as vectors for disease transmission to humans (e.g., cucumber, potato, June, and snout beetles; corn-earworm, cotton-bollworm, and grain moths; leafhoppers and mosquitoes) (Ducummon, 2000; Kunz et al., 2011). Boyles et al. (2011) estimated the annual value of bats to U. S. agriculture was at least \$3.7 billion, and could range as high as $\$ 53$ billion, in reduced crop losses and pesticide applications. Given the benefits of bats to agriculture and people, and the threat bats are currently facing with WNS, bat recovery efforts are of growing concern in many U.S. states.

Private landowners are an important target audience for conservation practitioners. Bat survivorship in the two weeks post hibernation (when bats migrate from maternal colonies to summer roosts) may be a critical time (Fuller et al., 2020). During the weeks when bats migrate from maternity colonies to summer roosts, private lands provide important habitat as bats forage and explore trees and buildings for suitable roosts (Best \& Jennings, 1997; Caceres \& Barclay, 2000; Fujita \& Kunz, 1984; Thompson, 1982). In 2005, a landowner survey in northern New York indicated that $86 \%$ of landowners had experienced 
interactions with bats on their property (Kretser et al. 2009). Landowners could play a significant role in recovery of bat populations affected by WNS by using forest management practices that retain a mix of live, dead, and dying trees for roost sites; create small forest openings for bat foraging; and retain or create clean, pooled sources of water (Lacki, 2006). Private landowners also can contribute to bat conservation through indirect actions, such as supporting organizations that conserve bats and encouraging others to engage in actions that conserve bats.

As part of recovery efforts, persuasive communication will be important in building support for initiatives and actions that conserve bats. Boyles et al. (2011) argued that political and financial support for initiatives that conserve bats, as well as promotion of positive human behaviors, depend on the degree that ordinary citizens understand and value the economic and ecological benefits provided by bat species. But, creating awareness of such benefits may not be enough to motivate actions that conserve bats. Encouraging bat conservation is challenging because, although bat species are threatened by human activities, they also present threats to humans (Allocati et al. 2016). Bats can be a source of rabies infections in humans and bats' accumulated excrement in buildings can create conditions favorable for other pathogens that are harmful to humans. North American bats have been found to harbor some types of coronaviruses, which has raised concern about the possible role of bats in emergent zoonotic diseases (Dominguez et al. 2007).

Species of wildlife that are threatened by humans and also threatening to humans (e.g., sharks, mountain lions, bats) are often depicted in mass media as both vulnerable and threatening; depicting these species as "scary victims" can send mixed messages that make conservation of those species more challenging (Bomieri et al., 2018; Muter et al., 2013). Governmental and nongovernmental organizations may also send messages that emphasize only threats to or threats from bats, but not both. Common risk messages from public health 
officials emphasize how people can protect themselves from the risk of becoming infected with rabies or otherwise exposed to related hazards from bats living in or around man-made structures. For example, a rabies prevention brochure currently used in New York State warns residents not to touch or attract wildlife, including bats (https://www.health.ny.gov/publications/3011.pdf). However, messages from public health agencies that warn people to stay away from bats may seemingly conflict with conservationrelated messages from nongovernmental conservation groups that encourage people to build bat houses or otherwise attract bats to their properties. It is unclear how different and sometimes contradictory messages from governmental agencies and the media correlate with the general public's intentions to take actions that conserve bats.

Effective communication strategies included in WNS-management efforts should be founded on an understanding of human attitudes, beliefs, and behaviors related to bats. Messages derived without an understanding of target audiences may be ineffective at mobilizing people to engage in recovery of bats. In this paper we report results from a study of New York State property owners to identify variables that predicted intentions to take actions to help conserve bats.

\section{Conceptual Framework and Hypotheses}

We grounded our study in protection motivation theory (PMT; Maddux \& Rogers, 1983; Prentice-Dunn \& Rogers, 1986; Rogers, 1975, 1983) and other literature that addresses how people respond to risk and information about risk reduction. Based on this literature, we crafted hypotheses about predictors of intentions to take actions that conserve bats, considering that people may have concerns about both bat conservation and rabies prevention. Our hypotheses are described below and shown in Figure 1.

Figure 1 about here 


\section{Hypotheses Based on Protection Motivation Theory}

The components of PMT have been integrated into persuasive communication campaigns with a variety of goals (e.g., changing behavior with respect to preventative health, disaster preparedness, environmental protection; Cismaru et al., 2011). Floyd et al., (2000) argued that PMT concepts can be used for understanding "any threat for which there is an effective recommended response that can be carried out by an individual" (p. 409). The theory posited that behaviors to prevent an undesirable outcome (e.g., illness, injury, property damage in a flood) are explained by five factors: (a) perceived severity of the undesirable outcome; (b) perceived vulnerability to the undesirable outcome; (c) perceived self-efficacy (i.e., belief that one is capable of completing recommended actions); (d) perceived responseefficacy (i.e., belief that taking recommended actions will prevent or mitigate the undesirable outcome); and (e) perceived costs of implementing the recommendations (Cismaru et al., 2011). As Cismaru et al. (2011, p. 65-66) wrote, "PMT assumes that if individuals are presented with a clear and real threat and provided recommendations that must be followed to avoid or mitigate the threat (Perloff \& Ray, 1991), then they will adopt the recommended behavior if the recommendations are perceived as doable and easy to follow (Cismaru et al., 2009; McKenzie-Mohr \& Smith, 2008).” Evaluative research on a range of PMT applications (Floyd et al., 2000; Milne et al., 2000) has supported the hypotheses that elevating levels of perceived threat and efficacy, and decreasing perceived costs of action, increase the likelihood that a person will adopt the recommended behavior.

The PMT framework was developed and has been widely used for understanding the effects of fear appeals on attitudes and behaviors (Cismaru et al., 2011). In some cases, social marketing campaigners have explicitly reported how PMT was used as the theory underlying their campaigns to encourage preventative health behavior (Lefebvre, 2000), but often the theory underlying a behavior change intervention has not been stated (Luca \& Suggs, 2013). 
For example, Cismaru et al. (2011) reviewed 11 climate change campaigns and found that all incorporated at least four of the five variables posited by PMT in communication materials, but the underlying theory for those campaigns was not articulated on campaign websites or written materials.

We are not aware of any rabies prevention or bat conservation campaigns in which PMT is explicitly acknowledged as a theoretical foundation, but we believe that PMT can be a useful framework for understanding both rabies prevention and bat conservation campaigns because PMT components are evident in those campaigns. For example, a global coordinated approach to elimination of rabies worldwide has communicated with dog owners using messages that appear to be based in elements of PMT (WHO, WOAH, FAO, \& GARC, 2019). In the case of a dog vaccination and education campaign in Tanzania, flyers contained the message: "Rabies is a deadly disease, but we can prevent it. Protect yourself and your family." Messaging at dog vaccination clinics was coordinated to emphasize that rabies is a disease with severe consequences, that all people are vulnerable to the disease, that individuals have the power (i.e., self efficacy) to reduce their personal exposure to rabies by taking simple actions, and that public officials have identified effective ways for society to minimize human exposure to rabies (i.e., response efficacy is high). Bat conservation campaigns have emphasized that WNS is often fatal to North American bats and is decimating bat populations (i.e., high severity), that WNS is a highly contagious disease to which all colonial bats are vulnerable, that individuals have the power (i.e., self efficacy) to contribute to bat conservation through individual actions, and wildlife conservationists have identified effective ways to help conserve imperilled bat species (i.e., high response efficacy). These types of messages have been communicated in educational brochures, videos, podcasts, and other materials developed by the WNS response team (https://www.whitenosesyndrome.org). 
Public engagement in bat conservation occurs within a milieu of competing and conflicting messages about bats and human health. Messages from public health and bat conservation practitioners have typically striven to raise both threat appraisal and coping, with the goal of stimulating protection motivation and adoption of preventative health actions or bat conservation actions. But, because they have different objectives, public health and bat conservation practitioners have emphasized different messages and may have recommend incompatible behaviors. For example, Kretser et al. (2014) documented that press releases from public health agencies focused on the risks of rabies to humans and how humans should protect themselves from bats, whereas press releases from state wildlife agencies emphasized the need for protecting bats.

Some conservation practitioners have raised concerns that recent scientific literature on transmission of zoonotic diseases, such as rabies and Ebola, may be giving rise to fearraising stories about bats in popular media. López-Baucells et al. (2018), for example, completed a systematic review of 135 scientific publications between 1936 and 2016 that contained the words "bats" and "virus" in the title. They found that $51 \%$ of those publications characterized bats as a major concern for public health, but only $4 \%$ mentioned the ecosystem services of bats. Kasperson et al. (1988) described how mass media coverage of threats can amplify risk perceptions among consumers of mass media. López-Baucells et al. (2018) argued that biased framing of bat-related risks in scholarly publications could be amplified beyond scholarly circles through mass and social media platforms, compromising public acceptance of bats or support for initiatives that conserve bats. Similarly, Tuttle (2017) argued that misleading science reporting to lay audiences has sensationalized bat-related risks to human health, raising fear of bats and hindering conservation efforts. Messages that contain fear appeals (Ruiter et al., 2014) may predispose fear of bats or rabies, stimulating a defensive motivation, rejection of bat conservation messaging, and failure to engage in 
behaviors that conserve bats. Review of PMT and other literature led us to five research hypotheses:

$\mathrm{H}_{1-2}$ : Residents who believe bats are highly vulnerable to WNS $\left(\mathrm{H}_{1}\right)$ and WNS has severe consequences for bats $\left(\mathrm{H}_{2}\right)$ will report higher intentions to take actions that conserve bats.

$\mathrm{H}_{3-4}$ Residents who believe people are highly vulnerable to rabies $\left(\mathrm{H}_{3}\right)$ and rabies has severe consequences for people $\left(\mathrm{H}_{4}\right)$ will report lower intentions to take actions that conserve bats.

$\mathrm{H}_{5-6}$ : Residents who have a strong sense of self $\left(\mathrm{H}_{5}\right)$ and response efficacy $\left(\mathrm{H}_{6}\right)$ will report higher intentions to take actions that conserve bats.

\section{Hypotheses Based on Other Literature}

Although limited literature exists on factors predicting actions to conserve bats, other literature suggests connections between value orientations, attitudes, and wildlife conservation actions. Value orientations are assumed to be related to wildlife-related beliefs and attitudes, and subsequently, wildlife-related behavioral intentions and behaviors (Manfredo et al., 2004). Decisions about whether to take conservation actions could be guided by egoistic, altruistic, or biospheric value orientations (Stern \& Dietz, 1994). Theoretically, a person with a strong biospheric value orientation considers the costs and benefits that their decisions will have for ecosystems (Stern \& Dietz, 1994). Strong biocentric value orientation (de Groot \& Steg, 2007a, 2007b) has been linked to pro-environmental beliefs and behaviors (Steg \& de Groot, 2012). We expected to find that property owners with a strong biospheric value orientation would feel a moral obligation to prevent extinction of bat species, and thus would be more willing than other property owners to take actions that conserve bats. 
Social psychologists have theorized that individuals look for causal explanations of issues they encounter and such causal attribution is linked to their designation of responsibility for addressing the issues (Kelley, 1967; Weiner, 1995). In the context of bat conservation, we expected property owners who have a strong biospheric value orientation to also believe that human activities can endanger or sustain bat populations, and accordingly, that they bear some personal responsibility for bat conservation. A sense of personal responsibility for environmental quality has been associated with pro-environmental behavior (Bamberg \& Moser, 2007; Hines et al., 1987). This literature led to two hypotheses:

$\mathrm{H}_{7-8}$ : Residents who have a strong biospheric value orientation $\left(\mathrm{H}_{7}\right)$ and a sense of personal responsibility for bat conservation $\left(\mathrm{H}_{8}\right)$ will report higher intentions to take actions that conserve bats.

Evidence suggests that attitudes toward bats also may predict intentions to take actions that conserve bats (Fishbein \& Ajzen, 2010). Fagan et al. (2018) found that positive attitudes toward bats were predictive of support for efforts to protect bats in buildings near Great Smoky Mountains National Park. This information led us to $\mathrm{H}_{9}$.

$\mathrm{H}_{9}$ : Residents who have positive attitudes toward bats will report higher intentions to take actions that conserve bats.

Research by Manfredo and colleagues suggested that urbanization of the U. S. population over the last half of the $20^{\text {th }}$ century has driven a shift in wildlife value orientations away from utilitarianism and toward mutualism (Manfredo et al., 2003; Manfredo et al., 2009). Other research has suggested that differences in environmental concern across rural and urban residence have been diminishing (Hunter \& Brehm, 2004; Jones et al., 2003; Morrissey \& Manning, 2000). Given these trends, we were not anticipating rural-urban differences in biospheric value orientations. We did, however, expect rural residents to have more personal experiences with bats, and thus less fear of bats. We also 
speculated that rural people might be more likely to see bats as beneficial and worthy of conservation because they are closer to the agricultural fields that can benefit from insect control by bats. This information led to $\mathrm{H}_{10}$.

$\mathrm{H}_{10}$ : Residents who live in a rural area will report higher intentions to take actions that conserve bats.

\section{Methods}

\section{Study Area and Sampling Strategy}

Our study area was the 14-county area in eastern upstate New York where WNS had been detected. From that study area, we focused on counties that included part of a metropolitan statistical area (MSA). We did this to draw samples from both rural and urban populations. There are three MSAs in our study area: the Glens Falls, Albany-SchenectadyTroy, and Kingston. Within these MSAs there are five counties where WNS has been detected (Warren, Washington, Schoharie, Albany, Ulster). To lower sampling cost, we sampled from one county in each MSA: Warren (Glens Falls MSA), Albany (AlbanySchenectady-Troy MSA), and Ulster (Kingston MSA).

We defined urban areas as those having a population density of $>1,000$ people per square mile. There were 16 urban areas that fit that criterion (two in Warren County, 11 in Albany County, three in Ulster County). We selected one urban area in each county from which to draw subsamples (i.e., Cohoes in Albany County, Glens Falls in Warren County, Kingston in Ulster County). We selected these sites because they had similar population sizes. We drew the total urban sample $(n=1,250)$ in proportion to the number of residential property owners in each location (27\% from Warren County, 30\% from Albany County, 44\% from Ulster County).

We defined rural areas as those having $<100$ people per square mile and we identified 17 areas that fit this criterion. In each county, we selected two adjacent rural townships. We 
selected townships that represented approximately the same population size in each county (Thurman and Warrensburg in Warren County, Rensselaerville and Westerlo in Albany County, Denning and Olive in Ulster County). We drew the total rural sample $(n=1,250)$ in proportion to the number of residential property owners in each location (34\% from Warren County, 34\% from Albany County, 32\% from Ulster County). We selected our sample from the residential property tax codes for one-, two-, and three-family year-round residences, estates, rural residences with acreage, primarily residential property with agricultural production, and recreational use property.

\section{Survey Implementation}

We designed a survey instrument to assess: (a) attitudes toward bats; (b) knowledge about bats, WNS, and rabies; (c) biospheric value orientation; (d) components of PMT; (e) beliefs about responsibility for bat conservation; (f) actions to conserve bats; and (c) sociodemographic characteristics. The survey instrument can be obtained by contacting the corresponding author. Survey implementation followed a modified version of the Tailored Design Method (Dillman et al., 2014) and took place in April and May 2018. Each member of the sample was contacted up to four times (an initial letter and questionnaire, a reminder postcard, a second reminder letter and replacement questionnaire, and a final reminder about one week after the third mailing).

To assess potential nonresponse bias, we contracted the Survey Research Institute (SRI) at Cornell University to complete follow-up telephone interviews with 50 urban and 50 rural nonrespondents in three counties (Albany $[n=30]$, Ulster $[n=40]$, and Warren $[n=$ 30]). SRI completed nonrespondent interviews in June and July 2018. Interviews contained 15 questions from the mail questionnaire (i.e., questions on knowledge about bats, rabies, and WNS; experience with bats; attitudes toward bats; and sociodemographics). We assessed knowledge about bats, rabies, and WNS on a 7-point scale (from 0 for not at all 
knowledgeable to 6 for extremely knowledgeable). We also asked respondents and nonrespondents whether they thought four statements about bats, rabies, and WNS were true or false (response options: $1=$ true, $2=$ false, $3=$ not sure). Two of the statements (i.e., Bats help to control agricultural insect pests; When people visit caves, they may spread white-nose syndrome in bats without knowing it) were true. The other two statements (i.e., Hundreds of people die in the United States each year from rabies; People can get sick from the fungus that causes white-nose syndrome) were false.

\section{Dependent Variable}

We constructed separate 3-item scales to measure intentions to take direct or indirect behaviors to conserve bats within the year following the survey. All items were measured on a 7-point scale $(1=$ extremely unlikely to $7=$ extremely likely). We averaged responses to create both scales. The higher the score, the higher the respondent's intentions to take actions that conserve bats (Table 1).

Table 1 about here

\section{Independent Variables}

Independent variables included: components of PMT (i.e., perceived vulnerability to and severity of rabies or white-nose syndrome; bat conservation self efficacy; bat conservation response efficacy); biospheric value orientations; perceived responsibility for bat conservation, attitudes toward bats, and residence location. Threat appraisal constructs (i.e., severity, vulnerability) were measured with single items related to rabies (with the referent being one's own health) and related to WNS (with the referent being the health of bat populations). We measured perceived severity of consequences (from people getting rabies and bats getting WNS $)$ on a 6 -point scale $(1=$ not severe at all to $6=$ extremely severe). We measured perceived vulnerability (that people in New York will get rabies, or that bats in New York will get WNS) on a 6 -point scale $(1=$ not at all likely to $6=$ extremely 
likely). We used single items to measure bat conservation self efficacy (“There are things I can do to help with bat conservation") and response efficacy ("I believe that by working together people will be able to conserve bats in New York"). Both measures used a 7-point scale $(1=$ strongly disagree to $7=$ strongly agree $)$.

Biospheric value orientation (Schultz, 2001) was measured as the mean of a 7-item scale (Cronbach's $\alpha=.85, M=5.88, S D=0.98)$. The individual items within the scale had 7 response options $(1=$ strongly disagree to $7=$ strongly agree $)$. One item (i.e., "Plants and animals exist primarily to be used by humans") was reverse coded. Agreement with statements indicated a biospheric value orientation.

State residents' responsibility for bat conservation was measured using a single item with 7 response options that ranged from no responsibility at all (0) to complete responsibility (6). A higher score indicated sense of greater responsibility for bat conservation.

Attitudes toward bats were measured as the mean of a 7-item scale (Cronbach $\alpha=.78$, $M=5.22, S D=1.04)$. We asked respondents to indicate the extent they agreed bats were harmless, worthless (reverse-coded), vulnerable, attractive, frightening (reverse-coded), beneficial, or interesting. Each question had 7 response options $(1=$ strongly disagree to $7=$ strongly agree). We averaged responses to create a scale measuring attitudes toward bats. The higher the score, the more positive attitudes respondents had about bats. We adapted this approach from Lu et al. $(2017,2020)$.

Residence location was measured with a single question with three response options $(1=$ rural area with few neighbors, $2=$ outside town with scattered neighbors, $3=$ town/city with many neighbors). Although we sampled people from both urban and rural areas, we added this item to measure residential location because we recognized that variability in residence types existed in areas that were predominantly urban and rural. 


\section{Analyses}

We calculated descriptive statistics (frequencies, means) to compare results for each variable across rural and urban/suburban residents. We used Pearson's chi square tests and independent samples $t$-tests to test for differences between respondents and nonrespondents at the $p<.05$ level.

Preliminary analysis revealed no difference between the urban and rural respondents on several topics (e.g., knowledge about rabies and WNS, attitudes toward bats, biospheric value orientations, conservation efficacy, beliefs about responsibility residents should have for bat conservation). The differences we detected between urban and rural respondents (e.g., urban respondents perceived themselves as less knowledgeable than rural respondents) did not appear to be of practical importance. We therefore made a decision to combine the rural and urban respondent groups for analysis of factors that predicted intentions to take actions that conserve bats.

We used ordinary least squares linear regression to test models of intentions to take actions that conserve bats. We hypothesized that 10 independent variables would predict these intentions. Prior to conducting regression analysis, we used correlational statistics (i.e., Pearson's correlation coefficient, variance inflation factor [VIF]) to assess possible relationships among our 10 independent variables. We found that Pearson correlations were $<$ .60 for all pairs of independent variables (Table 2). We also found that VIF values between pairs of predictor variables were all low (range $=1.03-2.06$ ), indicating acceptably low levels of multicollinearity. Given these results, we retained all 10 independent variables in our regression model. Independent variables were entered into the model all at once.

Table 2 about here 


\section{Results}

\section{Descriptive Statistics}

We received 686 completed questionnaires for a 30\% response rate after deleting 240 undeliverable questionnaires from the original sample of 2,500. The majority of respondents $(55 \%)$ were male. Thirty-two percent of respondents lived in a rural area with few neighbors, $22 \%$ lived outside town with scattered neighbors, and $46 \%$ lived in a town/city with many neighbors.

Nonresponse analysis. Nonrespondents and respondents did not differ with regard to perceived knowledge about bats or WNS. Although nonrespondents were more likely than respondents to perceive themselves as highly knowledgeable about rabies $(M=4.73, S D=$ 1.57 vs. $M=3.14, \mathrm{SD}=1.66 ; t[767]=9.38, p<.001, \mathrm{~d}=0.917,95 \% \mathrm{CI}[0.71,1.11])$, nonrespondents also were more likely to respond "true" to the false statement, "hundreds of people die in the United States each year from rabies" (50\% nonrespondents vs. $20 \%$ respondents, $\chi^{2}[2, N=713]=69.28, p<.001$, Cramer's $\left.\mathrm{V}=.312, \mathrm{p}<.001\right)$. They also were more likely to respond "true" to the false statement, "people can get sick from the fungus that causes WNS" (45\% nonrespondents vs. 8\% respondents, $\chi^{2}(1, N=612)=121.94, p<.001$, Cramer's $\mathrm{V}=.414, \mathrm{p}<.001)$. Nonrespondents were no more likely to agree that bats are frightening (33\% nonrespondents vs. $36 \%$ respondents) $\left(\chi^{2}[1, N=706]=0.26, p=.263 ; \phi=\right.$ $.019, \mathrm{p}=.608)$, but were slightly less likely to agree that bats are beneficial $(80 \%$ nonrespondents vs. $91 \%$ respondents $\left(\chi^{2}[1, N=697]=10.02, p=.001 ; \phi=-.119, \mathrm{p}=.001\right)$. The proportions of respondents and nonrespondents who lived in towns/cities, outside towns, or in rural areas was the same. Respondents were more likely than nonrespondents to be male (55\% respondents vs. $45 \%$ nonrespondents, $\chi^{2}[1, N=699]=3.75, p=.053 ; \phi=.073$, $\mathrm{p}=.053)$ ). We did not make adjustments for respondent-nonrespondent differences in our analysis. 


\section{Components of Protection Motivation Theory}

Many respondents believed that the consequences of WNS for bats in New York could be severe $(M=4.56, S D=1.48) ; 59 \%$ perceived the consequences of WNS as 5 or 6 on a scale of $0=$ not severe at all to $6=$ extremely severe). About $50 \%$ of respondents believed it was likely that bats in New York would get WNS $(M=3.86, S D=1.35 S D)$. More than half of respondents $(55 \%)$ believed that the likelihood of people in New York getting rabies was low $(0$ or 1 on a scale of $0=$ not likely at all to $6=$ extremely likely; $M=1.71, S D=1.41)$. They expressed mixed views on the severity of consequences of people getting rabies $(M=3.90$, $S D=1.92)$, although nearly half $(47 \%)$ perceived the consequences as severe $(5$ or 6 on a scale of $0=$ not severe at all to $6=$ extremely severe). Perceived level of bat conservation self efficacy was relatively high $(M=5.42, S D=1.32) ; 73 \%$ agreed with the statement, "There are things I can do to help with bat conservation.” Perceived level of bat conservation response efficacy was also high $(M=5.84, S D=1.13) ; 86 \%$ agreed with the statement, "I believe that by working together people will be able to conserve bats in New York."

\section{Biospheric Value Orientation and Responsibility}

Most respondents held a strong biospheric value orientation (grand mean for all respondents was 5.89 on a scale of $1=$ least biospheric to $7=$ most biospheric). For example, $94 \%$ agreed that humans have a moral obligation to ensure that we do not cause extinction of other species, and $70 \%$ agreed that every species has equal value and an equal right to exist. Respondents believed that wildlife management agencies $(M=4.55, S D=1.34)$ and nongovernmental conservation organizations $(M=4.33, S D=1.33)$ should have more responsibility than state residents $(M=3.69, S D=1.46)$ for bat conservation. Even so, nearly all respondents (97\%) believed New York State residents bear some responsibility for bat conservation $(M=3.69, S D=1.46)$.

\section{Attitudes toward Bats}


Most respondents held positive attitudes toward bats. The grand mean for all respondents on the attitude scale was $5.22( \pm 1.04 S D)$. A majority of respondents agreed that bats are beneficial $(M=6.12, \pm 1.28 S D)$, vulnerable $(M=5.32, \pm 1.56 S D)$, harmless $(M=$ $4.75, \pm 1.69 S D)$, and interesting $(M=5.64, \pm 1.47 S D)$. Most $(83 \%)$ had seen a bat in their neighborhood and knew that bats help control insect populations (93\%). Few (19\%) reported having had a bad experience with a bat.

\section{Behavioral Intentions}

Few respondents said they were moderately or extremely likely to take direct or indirect actions that conserve bats within the next 12 months; the proportion ranged from $6 \%$ (for joining or supporting a bat conservation group) to $21 \%$ (for improving bat habitat on their property) (Table 1).

\section{Predictors of Bat Conservation Intentions}

We calculated models to predict behavioral intentions using 10 hypothesized independent variables. Multiple linear regression explained 39\% of the variance in intention to take direct actions that conserve bats $(F[10,434]=53.42,, p<.001)$ and $27 \%$ of the variance in indirect actions that conserve bats $(F[10,434]=53.42,, p<.001)$. The best predictor of direct or indirect actions to conserve bats was perceived level of responsibility that state residents should have for bat conservation (Table 1). Results from both models provide support for hypotheses $\mathrm{H}_{8}$ and $\mathrm{H}_{9}$; in both models the more that respondents believed that residents share responsibility for conservation of bats, and the more positive their attitudes toward bats, the greater their intentions to take actions to conserve bats. Believing that the effects of rabies on people are severe, and believing that one can do things to conserve bats (self efficacy) were predictive of greater intentions to take direct actions. Holding a strong biospheric value orientation was predictive of greater intentions to take indirect actions. These results provided partial support for $\mathrm{H}_{4}, \mathrm{H}_{5}$, and $\mathrm{H}_{7}$, respectively. The 
other independent variables had no predictive relationships with actions to conserve bats, providing no support for $\mathrm{H}_{1}, \mathrm{H}_{2}, \mathrm{H}_{3}, \mathrm{H}_{6}$, or $\mathrm{H}_{10}$ (Table 3).

\section{Table 3 about here}

\section{Discussion}

The conservation actions of private citizens are one important component of sustaining North American bat species in the face of disease threats and habitat loss. Although persuasive communication has been used for encouraging more citizens to engage in actions to conserve bats, scholarship to inform those efforts has been sparse. We addressed this information gap by testing models to predict intentions to conserve bats. Five independent variables were predictors of these intentions, but the set of predictors differed across models. Severity of rabies for people and bat conservation self efficacy were predictive only in the direct actions model. The finding that perceived severity of rabies was inversely related to taking direct actions that conserve bats was consistent with PMT. People who perceive severe consequences of rabies may be disinclined to build bat houses at their residence or improve bat habitat on their property, actions that in their mind might increase their proximity to bats and exposure to what is otherwise considered a low risk event (i.e., exposure to a rabid bat). The positive relationship between self-efficacy (Bandura 1977, 1997) and intentions to take direct actions to conserve bats was consistent with a body of

research that has demonstrated a correlation between self-efficacy, behavior, and behavioral intentions in other contexts, such as preventative health and disaster preparedness (Floyd et al., 2000; Milne et al., 2000).

According to cognitive hierarchy theory variables such as value orientation, beliefs and attitudes mediate the value-behavior relationship. We expected to find an association between value orientation and behavioral intentions. Biospheric value orientation only predicted intentions to take indirect actions to conserve bats. This was consistent with past 
studies demonstrating a correlation between a strong biospheric value orientation and proenvironmental intentions or actions (de Groot \& Steg, 2009). Indirect actions to conserve bats (e.g., donating to bat conservation organizations) may be a tangible outward expression of one's underlying biospheric value orientation.

The finding that positive attitudes toward bats and a sense of personal responsibility for bat conservation were predictive of conservation intentions was also consistent with previous research. Other studies have demonstrated a relationship between positive attitudes toward a species and support for conservation of that species (Liordos et al., 2017). Our findings on resident responsibilities for bat conservation are consistent with previous research linking attributions of responsibility to behavioral intentions (Hines et al., 1987; Kaiser et al., 1999).

The linkages we found between positive attitudes, sense of personal responsibility, and intentions to conserve bats were also consistent with findings on motivations to participate in conservation citizen science projects. Davis et al. (2019) found that increased participation in a citizen science project focused on surveillance of urban cockatoos was better predicted by residents' attitudes toward urban wildlife than by their pro-environmental values. Maund et al. (2020) found that the best predictor of participation in a citizen science project to monitor wildlife health in Britain was a 10-item index that included themes such as love of wildlife and nature, concern about animal welfare and species conservation, and a personal interest in doing one's part to help wildlife and nature.

In preventative health studies, threat appraisal variables (severity, vulnerability) have tended to be less predictive of behavioral intentions than coping appraisal variables (self and response efficacy; Floyd et al., 2000; Milne et al., 2000). Contrary to our expectations, perceptions about bat vulnerability to WNS, severity of WNS for bats, and human vulnerability to rabies were not predictors of behavioral intentions. We speculate that 
knowledge of WNS was so limited, and perceptions of the impacts of WNS on bats were so inchoate, that they had no measureable effect on intentions to conserve bats. Vulnerability to rabies may not have been predictive because most respondents believed that New York State residents were unlikely to contract rabies.

\section{Study Limitations}

Although this study produced important insights, it had several methodological limitations that should be addressed in future research. In retrospect, our operationalization of response efficacy may have been too broad to test the linkage between intentions to take specific actions and the perceived effectiveness of those specific actions in conserving bats. There are several possible explanations for the nonsignificant results related to residence location: our measure of rurality may have been inadequate, the absence of large cities in our study area may have constrained variation in rural/urban differences, or the concept of rurality may be losing meaning in areas where all residents have similar access to bat- and rabies-related information and experiences. A previous study in a portion of our study area found that urban/rural background was not predictive of whether northern New York residents viewed their interactions with local wildlife as positive (Kretser et al., 2009).

Although appropriate for hypothesis testing, the sampling approach we employed precludes generalization from respondent characteristics to the entire populations within the counties from which the samples were drawn. Differences we detected between respondents and nonrespondents give further reason for caution about generalizing from this study to the larger population. Our findings are most applicable to people who have positive attitudes towards bats and are relatively knowledgeable about WNS and rabies. This research should be replicated on a broader scale, and with simple random sampling of key audiences for bat conservation campaigns. A specific target audience for communicating about bat conservation may hold more or less positive attitudes toward bats, and the drivers of their 
behavior could differ. It would be helpful to repeat this work in regions where WNS is not present (e.g., portions of the west coast of the U.S.) and in regions where bats may play a significant role in control of insect pests (e.g., cotton-growing regions of Texas or corngrowing regions of the Midwest). Differences in perceptions of threats to bat conservation and benefits to humans from bats may play a role in motivations to engage in bat conservation.

\section{Practical Implications and Directions for Future Research}

Our findings suggest that conservation practitioners should continue assuming that perceptions about rabies are a lens through which some of their audience filter messages, when weighing whether or not to engage in direct conservation actions. Knowing that fears about human health may predict involvement in bat conservation, practitioners should address those concerns directly while also encouraging accurate risk perceptions and informing people about the economic and environmental benefits of bats. Based on our findings, we echo recommendations by Lu et al. (2017) and Buttke et al. (2015) to develop balanced conservation messaging that addresses both public health threats from bats and anthropogenic threats to bats. Given that positive attitudes toward bats and a strong biospheric value orientation were predictive of intentions to conserve bats, we recommend that communicators emphasize the benefits of bats in their messaging. Emphasizing batrelated benefits to humans and ecosystems should resonate with those who already hold positive attitudes toward bats and may be predisposed to taking actions to conserve bats.

These findings suggest that messages which build a sense of self efficacy (e.g., communicating that the recommended actions are easy and inexpensive; providing clear guidance for how to carry out the actions; including stories about people who were able to carry out the actions successfully) could help promote direct behaviors that conserve bats. The message that bat conservation is everyone's responsibility may also be useful for 
encouraging both direct and indirect actions to conserve bats. Messages that integrate selfefficacy and personal responsibility themes should be tested as part of a larger communication strategy on bat conservation.

\section{References}

Allocati, N., Petrucci, A. G., Di Giovanni, P., Masulli, M., Di Ilio, C., \& De Laurenziov, V. (2016). Bat-man disease transmission: Zoonotic pathogens from wildlife reservoirs to human population. Cell Death Discovery, 16048. http://doi: $10.1038 /$ cddiscovery.2016.48

Bamberg, S., \& Moser, G. (2007). Twenty years after Hines, Hungerford, and Tomera: A new meta-analysis of psycho-social determinants of pro-environmental behavior. Journal of Environmental Psychology, 27, 14-25.

Bandura. A. (1977). Self-efficacy: Toward a unifying theory of behavioral change. Psychological Review, 84, 191-215.

Bandura, A. (1997). Self-efficacy: The exercise of control. Freeman.

Best, T. L., \& Jennings, J. B. (1997). Myotis leibii. Mammalian Species, 547, 1-6.

Blehert D. S., Hicks, A. C., Behr, M., Meteyer, C. U., Berlowski-Zier, B. W., Buckles, E. L., Coleman, J. T. H., Darling, S. R., Gargas, A., Niver, R., Okoniewski, J. C., Rudd, R. J., \& Stone, W. B. (2009). Bat white-nose syndrome: An emerging fungal pathogen? Science, 323(5911), 227. http://doi: 10.1126/science.1163874

Bombieri, G., Nanni, V., Delgado, M. D. M., Fedriani, J. M., Lopez-Bao, J. V., Pedrini, P., \& Penteriani, V. (2018). Content analysis of media reports on predator attacks on humans: Toward an understanding of human risk perception and predator acceptance. BioScience, 68, 577-584. 
Boyles, J. G., Cryan, P. M., McCracken, G. F., \& Kunz, T. H. (2011). Economic importance of bats in agriculture. Science, 332(6025), 41-42.

Buttke, D. E., Decker, D. J., \& Wild, M. A. (2015). The role of One Health in wildlife conservation: A challenge and opportunity. Journal of Wildlife Diseases, 51, 1-8.

Caceres, M. C., \& Barclay, R. M. R. (2000). Myotis septentrionalis. Mammalian Species, $634,1-4$.

Cismaru, M., Cismaru, R., Ono, T., \& Nelson, K. (2011). “Act on climate change”: An application of protection motivation theory. Social Marketing Quarterly, 17(3), 6284.

Cismaru, M., Lavack, A. M., \& Markewich, E. (2009). Social marketing campaigns aimed at preventing drunk driving: A review and recommendations. International Marketing Review, 26, 292-311.

Davis, A., Taylor, C. E., \& Martin, J. M. (2019). Are pro-ecological values enough? Determining the drivers and extent of participation in citizen science programs. Human Dimensions of Wildlife, 24, 501-514.

de Groot, J. I. M., \& Steg, L. (2009). Mean or green: Which values can promote stable proenvironmental behavior? Conservation Letters, 2, 61-66.

de Groot, J. I. M., \& Steg, L. (2007a). Value orientations and environmental beliefs in five countries: Validity of an instrument to measure egoistic, altruistic and biospheric value orientations. Journal of Cross-cultural Psychology, 38, 318-332.

de Groot, J. I. M., \& Steg, L. (2007b). Value orientations to explain beliefs related to environmental significant behavior: How to measure egoistic, altruistic, and biospheric value orientations. Environment and Behavior, 40, 330-354. http://doi: $10.1177 / 0013916506297831$ 
Dillman, D. A., Smyth, J. D., \& Christian, L. M. (2014). Internet, mail, and mixed-mode surveys: The tailored design method ( $4^{\text {th }}$ ed.). Wiley.

Dominguez, S. R., O’Shea, T. J., Oko, L. M., \& Holmes, K. V. (2007). Detection of Group 1 Coronaviruses in Bats in North America. Emerging Infectious Diseases 13(9): 12951300. http://doi: $10.3201 /$ eid1309.070491

Ducummon, S. L. (2000). Ecological and economic importance of bats. Bat Conservation International.

Fagan, K. E., Willcox, E. V., \& Willcox, A. S. (2018). Public attitudes toward the presence and management of bats roosting in buildings in Great Smoky Mountains National Park, Southeastern United States. Biological Conservation, 220, 132-139.

Fishbein, M., \& Ajzen, I. (2010). Predicting and changing behavior: The reasoned action approach. Psychology Press.

Floyd, D. L., Prentice-Dunn, S., \& Rogers, R. W. (2000). A meta-analysis of research on protection motivation theory. Journal of Applied Social Psychology, 30, 407-429.

Froschauer A, \& Coleman, J. (2012). North American bat death toll exceeds 5.5 million from white-nose syndrome. U.S. Fish \& Wildlife Service. http://www.batcon.org/pdfs/USFWS_WNS_Mortality_2012_NR_FINAL.pdf

Fujita, M. S., \& Kunz, T. H. (1984). Pipistrellus subglavus. Mammalian Species, 228, 1-6.

Fuller, N. W., McGuire, L. P., Pannkuk, E. L., Blute, T., Haase, C., Mayberry, H. W., Risch, T. S., \& Willis, C. K. R. (2020). Disease recovery in bats affected by white-nose syndrome. The Journal of Experimental Biology, 223. Article 211912. http://doi: $10.1242 /$ jeb. 211912

Ghanem, S. J., \& Voigt, C. C. (2012). Increasing awareness of ecosystem services provided by bats. Advances in the Study of Behavior, 44, 279-302. 
Hines, J., Hungerford, H. R., \& Tomara, A. N. (1987). Analysis and synthesis of research on responsible environmental behavior: A meta-analysis. Journal of Environmental Education, 18(2), 1-8.

Hunter, L. M., \& Brehm, J. M. (2004). A qualitative examination of value orientations toward wildlife and biodiversity by rural residents of the intermountain region. Human Ecology Review, 11, 13-36.

Jones, R. E., Fly, J. M., Talley, J, \& Cordell, H. K. (2003). Green migration into rural America: The new frontier of environmentalism? Society and Natural Resources, 16, 221-238.

Kaiser, F. G., Ranney, M., Hartig, T., \& Bowler, P. A. (1999). Ecological behavior, environmental attitude, and feelings of responsibility for the environment. European Psychologist, 4(2), 59-74.

Kasperson, R. E., Renn, O., Slovic, P., Brown, H. S., Emel, J., Goble, R., Kasperson, J. X., \& Ratick, S. 1988. The social amplification of risk: A conceptual framework. Risk Analysis, 8(2), 177-187.

Kasso, M., \& Balakrishnan, M. (2013). Ecological and economic importance of bats (Order Chiroptera). ISRN Biodiversity, 2013, Article ID 187415. http://doi.org/10.1155/2013/187415

Kelley, H. H. (1967). Attribution theory in social psychology. Nebraska Symposium on Motivation, 15, 129-238.

Kretser, H. E., Curtis, P. D., Francis, J. D., Pendall, R. J., \& Knuth, B. A. (2009). Factors affecting perceptions of human-wildlife interactions in residential areas of Northern New York and implications for conservation. Human Dimensions of Wildlife, 14, 102-118. 
Kretser, H., Lauber, B., Dixon, G., \& McComas, K. (2014, October 5-9). Inconsistent messages in state wildlife and public health agency communication about bats: potential impacts for conservation and recovery. [Paper presentation]. Pathways 2014: Integrating Human Dimensions into Fish and Wildlife Management, Estes Park, CO., United States.

Kunz, T. H., Braun de Torrez, E., Bauer, D., Lobova, T., \& Fleming, T. H. (2011). Ecosystem services provided by bats. Annals of the New York Academy of Sciences, $1223,1-38$.

Lacki M. J., Hayes J. P, \& Kurta, A. (2007). Bats in forests. Johns Hopkins University Press.

Lefebvre, R. C. (2000). Theories and models in social marketing. In P. N. Bloom \& G. T. Gundlach (Eds.), Handbook of marketing and society (pp. 506-519). SAGE Publications.

Liordos, V., Kontsiotis, V. J., Anastasiadou, M., \& Karavasias, E. (2017). Effects of attitudes and demography on public support for endangered species conservation. Science of the Total Environment, 595, 25-34.

López-Baucells, A., Rocha, R., \& Fernández-Llamazares, A. (2018). When bats go viral: Negative framings in virological research imperil bat conservation. Mammal Review, 48, 62-66. http://doi: 10.1111/mam.12110

Lu, H., McComas, K. A., Buttke, D. E., Roh, S., Wild, M. A., \& Decker, D. J. (2017). One Health messaging about bats and rabies: How framing of risks, benefits and attributions can support public health and wildlife conservation goals. Wildlife Research, 44, 200-206. doi.org/10.1071/WR16061

Lu, H. McComas, K., Kretser, H., \& Lauber, T. (2020). Scared yet compassionate? Exploring the order effects of threat versus suffering messages on attitude toward scary victims. Science Communication, 42, 3-30. 
Luca, N. R., \& Suggs, L. S. (2013). Theory and model use in social marketing health interventions. Journal of Health Communication: International Perspectives, 18, 20 40.

Maddux, J. E., \& Rogers, R. W. (1983). Protection motivation and self-efficacy: A revised theory of fear appeals and attitude change. Journal of Experimental Psychology, 19, 469-479.

Maine, J. J., \& Boyles, J. G. (2015). Bats initiate vital agroecological interactions in corn. Proceedings of the National Academy of Sciences (PNAS) 112(40), 12438-12443.

Manfredo, M. J., Teel, T. L., \& Bright, A. D. (2003). Why are public values toward wildlife changing? Human Dimensions of Wildlife 8, 287-306.

Manfredo, M. J., Teel, T. L., \& Bright, A. D. (2004). Applications of the concept of values and attitudes in human dimensions of natural resources research. In M. J. Manfredo, J. J. Vaske, B. L. Bruyere, D. R. Field, \& P. Brown (Eds.), Society and natural resources: A summary of knowledge (pp. 271-282). Modern Litho.

Manfredo, M. J., Teel, T. L., \& Henry, K. L. (2009). Linking society and environment: A multilevel model of shifting wildlife value orientations in the western United States. Social Science Quarterly, 90, 407-427.

Maund, P. R., Irvine, K. N., Lawson, B., Steadman, J., Risely, K., Cunningham, A. A., \& Davies, Z. G. (2020). What motivates the masses: Understanding why people contribute to conservation citizen science projects. Biological Conservation, 246, Article 108587. http://doi.org/10.1016/j.biocon.2020.108587

McKenzie-Mohr, D., \& Smith, W. (2008). Fostering sustainable behavior. An introduction to community-based social marketing. New Society Publishers. 
Milne, S., Sheeran, P., \& Orbell, S. (2000). Prediction and intervention in health related behavior: A meta-analytic review of protection-motivation theory. Journal of Applied Social Psychology, 30, 106-143.

Morrissey, J., \& Manning, R. (2000). Race, residence, and environmental concern: New Englanders and the White Mountain National Forest. Human Ecology Review, 7, 12 23.

Muter, B. A., Gore, M. L., Gledhill, K. S., Lamont, C., \& Huveneers, C. (2013). Australian and U.S. news media portrayal of sharks and their conservation. Conservation Biology, 27, 187-196.

Perloff, R. M., \& Ray, G. B. (1991). An analysis of AIDS brochures directed at intravenous drug users. Health Communication, 3, 113-125.

Prentice-Dunn, S., \& Rogers, R. W. (1986). Protection motivation theory and preventive health: Beyond the health belief model. Health Education Research, 1, 153-161.

Rogers, R. W. (1975). A protection motivation theory of fear appeals and attitude change. Journal of Psychology, 91, 93-114.

Rogers, R. W. (1983). Cognitive and psychological processing in fear appeals and attitude change: A revised theory of protection motivation. In J. T. Cacioppo \& R. E. Petty (Eds.), Socialpsychophysiology (pp. 153-176). Guilford Press.

Ruiter, R. A. C., Kessels, L. T. E., Peters, G.-J. Y., \& Kok1, G. (2014). Sixty years of fear appeal research: Current state of the evidence. International Journal of Psychology, 49(2), 63-70. http://doi: 10.1002/ijop.12042

Schultz, P. W. (2001). The structure of environmental concern: Concern for self, other people, and the biosphere. Journal of Environmental Psychology, 21, 327-339. http://doi: 10.1006/jevp.2001.0227 
Stern, P. C., \& Dietz, T. (1994). The value basis of environmental concern. Journal of Social Issues 50, 65-84.

Steg, L., \& de Groot, J. I. M. (2012). Environmental values. In S. Clayton (Ed.), The Oxford handbook of environmental and conservation psychology (pp. 81-92). Oxford University Press.

Thompson, C. E. (1982). Myotis sodalist. Mammalian Species, 163, 1-5.

Tuttle, M. (2017). Fear of bats and its consequences. Journal of Bat Research \& Conservation, 10(1). http://doi.org/10.14709/BarbJ.10.1.2017.09

Weiner, B. (1995). Judgments of responsibility: A foundation for a theory of social conduct. Guilford Press.

World Health Organization (WHO), World Organisation for Animal Health (WOAH), Food and Agriculture Organization (FAO), Global Alliance for Rabies Control (GARC). (2019). Zero by 30: The global strategic plan to end human deaths from dogmediated rabies by 2030. http://apps.who.int/iris/handle/10665/272756 
Table 1. Likelihood of taking direct or indirect actions to conserve bats within the following 12 months among residential property owners in three New York State counties in May, 2018.

\begin{tabular}{|c|c|c|c|c|c|c|c|c|c|c|c|}
\hline \multirow[b]{2}{*}{ Conservation Behaviors } & \multirow[b]{2}{*}{$n$} & \multirow[b]{2}{*}{ M } & \multirow[b]{2}{*}{$S D$} & \multirow{2}{*}{$\begin{array}{c}\text { Cronbach's } \\
\text { alpha }\end{array}$} & \multicolumn{7}{|c|}{ Likelihood of taking action in next 12 months $^{\mathrm{a}}$} \\
\hline & & & & & 1 & 2 & 3 & 4 & 5 & 6 & 7 \\
\hline & & & & & $\%$ & $\%$ & $\%$ & $\%$ & $\%$ & $\%$ & $\%$ \\
\hline Direct Behaviors (scale) & 588 & 3.33 & 1.76 & .86 & & & & & & & \\
\hline Improve bat habitat on your property & 600 & 3.56 & 2.02 & & 27 & 11 & 8 & 18 & 16 & 13 & 7 \\
\hline Build bat houses at your residence & 598 & 3.24 & 2.11 & & 34 & 14 & 6 & 13 & 14 & 10 & 9 \\
\hline Help to monitor bats & 592 & 3.22 & 1.86 & & 29 & 13 & 9 & 24 & 12 & 9 & 4 \\
\hline Indirect Behaviors (scale) & 591 & 2.83 & 1.49 & .79 & & & & & & & \\
\hline Make donations to bat conservation groups & 596 & 3.04 & 1.84 & & 32 & 15 & 6 & 25 & 11 & 8 & 3 \\
\hline Contact legislators to request their support & 600 & 2.92 & 1.86 & & 37 & 14 & 5 & 23 & 10 & 8 & 3 \\
\hline for funding to study WNS & & & & & & & & & & & \\
\hline Join or support a bat conservation group & 596 & 2.57 & 1.65 & & 40 & 17 & 9 & 23 & 6 & 3 & 2 \\
\hline
\end{tabular}

${ }^{a} 1=$ Extremely unlikely, 2=Moderately unlikely, $3=$ Slightly unlikely, 4=Neither likely nor unlikely, 5=Slightly likely, $6=$ Moderately likely, $7=$ Extremely likely 
Table 2. Pearson correlations among independent variables in regression models.

\begin{tabular}{|c|c|c|c|c|c|c|c|c|c|c|}
\hline & $\mathrm{H}_{1}$ & $\mathrm{H}_{2}$ & $\mathrm{H}_{3}$ & $\mathrm{H}_{4}$ & $\mathrm{H}_{5}$ & $\mathrm{H}_{6}$ & $\mathrm{H}_{7}$ & $\mathrm{H}_{8}$ & $\mathrm{H}_{9}$ & $\mathrm{H}_{10}$ \\
\hline WNS: Vulnerability $\left(\mathrm{H}_{1}\right)$ & 1 & $.696 * *$ & .020 & $.178^{* *}$ & $223^{* *}$ & $.181^{* *}$ & $.136^{* *}$ & $.213^{* *}$ & $.273^{* *}$ & $.093^{*}$ \\
\hline WNS: Severity $\left(\mathrm{H}_{2}\right)$ & & 1 & -.068 & $.243^{* *}$ & $.319^{* *}$ & $.278^{* *}$ & $.209^{* *}$ & $.255^{* *}$ & $.350^{* *}$ & $.115^{* *}$ \\
\hline Rabies: Vulnerability $\left(\mathrm{H}_{3}\right)$ & & & 1 & $.283^{* *}$ & $-.236^{* *}$ & $-.182^{* *}$ & $-.204^{* *}$ & $-.220^{* *}$ & $-.424^{* *}$ & $-.083^{*}$ \\
\hline Rabies: Severity $\left(\mathrm{H}_{4}\right)$ & & & & 1 & .025 & -.008 & -.008 & -.008 & -.039 & -.014 \\
\hline Efficacy: Self $\left(\mathrm{H}_{5}\right)$ & & & & & 1 & $.662^{* *}$ & $.329^{* *}$ & $.384^{* *}$ & $.528^{* *}$ & $.134^{* *}$ \\
\hline Efficacy: Response (H6) & & & & & & 1 & $.439^{* *}$ & $.327^{* *}$ & $.495^{* *}$ & $.122^{* *}$ \\
\hline Biospheric orientation $\left(\mathrm{H}_{7}\right)$ & & & & & & & 1 & $.315^{* *}$ & $.364^{* *}$ & -.030 \\
\hline Responsibility: Residents $\left(\mathrm{H}_{8}\right)$ & & & & & & & & 1 & $.382^{* *}$ & .074 \\
\hline Attitudes toward bats $\left(\mathrm{H}_{9}\right)$ & & & & & & & & & 1 & .079 \\
\hline Residence location $\left(\mathrm{H}_{10}\right)$ & & & & & & & & & & 1 \\
\hline
\end{tabular}

$* p<.05 . * * p<.01$. 
Table 3. Multiple linear regression analyses for predictors of intention to take direct or indirect bat conservation actions.

\begin{tabular}{|c|c|c|c|c|c|c|}
\hline & \multicolumn{3}{|c|}{ Direct actions } & \multicolumn{3}{|c|}{ Indirect actions } \\
\hline & $\mathrm{B}$ & SE (B) & $\beta$ & $\mathrm{B}$ & SE (B) & $\beta$ \\
\hline WNS: Vulnerability $\left(\mathrm{H}_{1}\right)$ & .039 & .067 & .029 & .041 & .063 & .036 \\
\hline WNS: Severity $\left(\mathrm{H}_{2}\right)$ & .085 & .065 & .070 & .061 & .061 & .059 \\
\hline Rabies: Vulnerability $\left(\mathrm{H}_{3}\right)$ & .024 & .057 & .019 & .001 & .052 & .001 \\
\hline Rabies: Severity $\left(\mathrm{H}_{4}\right)$ & $-.130 * *$ & .037 & -.140 & -.045 & .035 & -.056 \\
\hline Efficacy: Self $\left(\mathrm{H}_{5}\right)$ & $.193 *$ & .074 & .140 & .025 & .070 & .021 \\
\hline Efficacy: Response $\left(\mathrm{H}_{6}\right)$ & -.002 & .082 & -.001 & .021 & .078 & .016 \\
\hline Biospheric orientation $\left(\mathrm{H}_{7}\right)$ & .019 & .077 & .010 & $.189 * *$ & .072 & .120 \\
\hline Responsibility: Residents ( $\left.\mathrm{H}_{8}\right)$ & $.349 * * *$ & .051 & .289 & $.306^{* * *}$ & .048 & .291 \\
\hline Attitudes toward bats $\left(\mathrm{H}_{9}\right)$ & $.476^{* * *}$ & .085 & .283 & $.307 * * *$ & .080 & .212 \\
\hline Residence location $\left(\mathrm{H}_{10}\right)$ & -.145 & .075 & -.073 & .025 & .070 & .015 \\
\hline \multirow[t]{2}{*}{ Intercept } & $-1.283 *$ & & & - & & \\
\hline & & & & $1.533^{* *}$ & & \\
\hline $\mathrm{R}^{2}$ & .40 & & & .29 & & \\
\hline Adjusted $\mathrm{R}^{2}$ & .39 & & & .27 & & \\
\hline
\end{tabular}




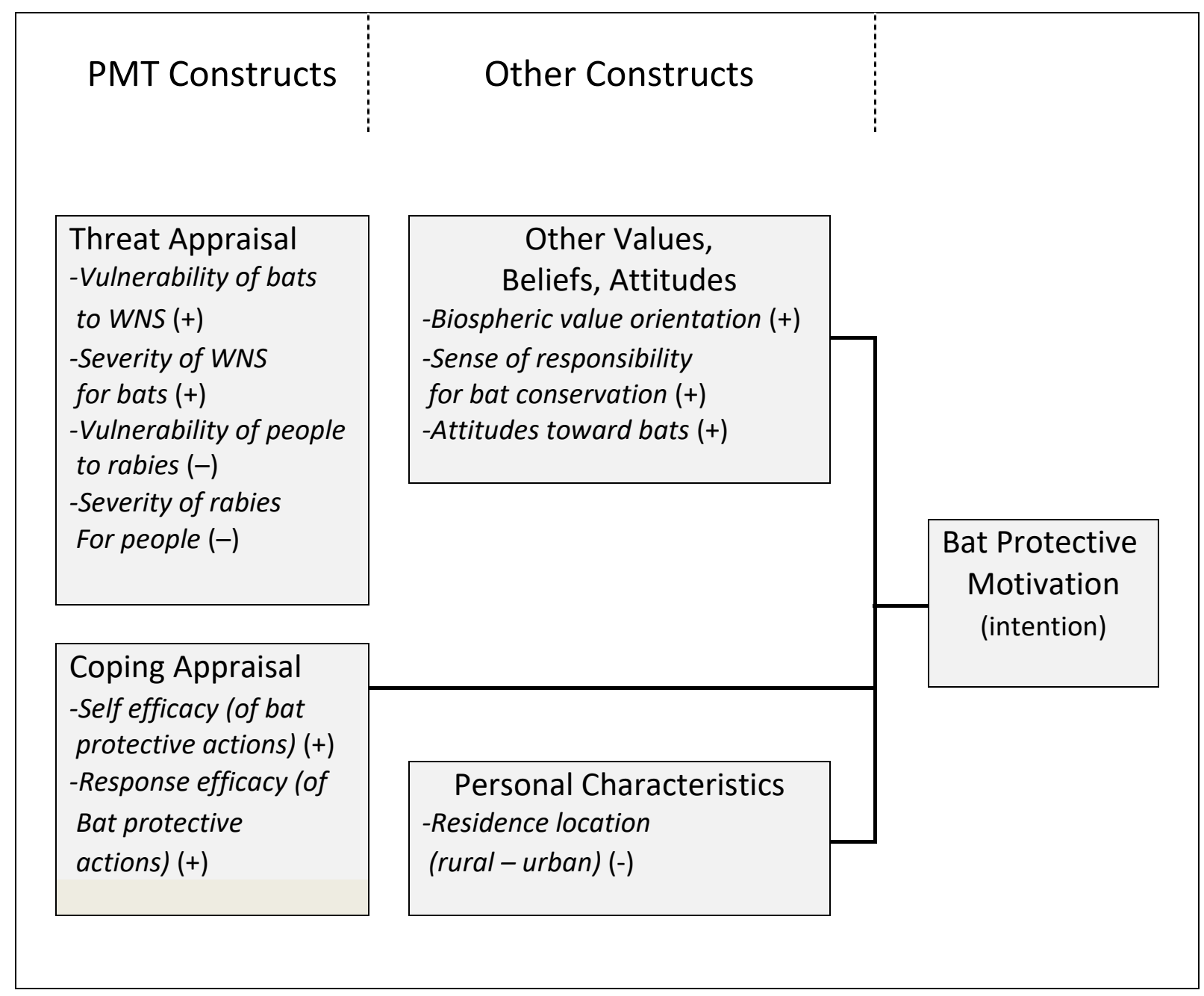

Figure 1. Conceptual model of factors affecting intentions to take actions that conserve bats 